\title{
A Cross-sectional Study on Sense of Coherence and Its Relationship with Caries Experience and Socioeconomic Status in 11-16-year-old Schoolchildren
}

\author{
Kantipudi JN Mrudhula ${ }^{1}$, C Vinay ${ }^{2}$, KS Uloopi ${ }^{3}$, Kakarla Sri RojaRamya ${ }^{4}$, Rayala Chandrasekhar ${ }^{5}$
}

\begin{abstract}
Aim: To know the association of sense of coherence (SOC), caries experience, and socioeconomic status (SES) in 11-16-year-old schoolchildren. Materials and methods: This cross-sectional study included a total of 595 schoolchildren aged 11-16 years, and informed consent was obtained. Demographic and socioeconomic data were collected through pro forma filled by the parents. Sense of coherence of children was recorded with SOC-13 item questionnaire given in both English and local language (Telugu). Caries experience was recorded with DMFT index by carrying out the intra-oral examination of children.

Results: In a total of 595 schoolchildren, 35\% children have weak SOC, 34.9\% have moderate SOC, and 29.9\% have strong SOC. Caries experience was inversely associated with SOC ( $p$ value $=0.006$ ) on analysis by ANOVA. On multivariate regression analysis, it was observed that for every one-unit increase in SOC, caries experience decreased by 0.11 unit. However, there was statistically no significant $(p$ value $=0.09)$ relation between childhood SES and SOC. Age ( $p$ value $=0.08$ ) and gender $(p$ value $=0.19)$ are not associated with SOC.

Conclusion: Sense of coherence influences the caries experience irrespective of socioeconomic status, age, and gender of the child.

Clinical significance: Children having stronger SOC have increased likelihood to seek out preventive dental services, which helps in maintaining good oral health. SOC is structured mainly by the experiences during the early years of life. Therefore, SOC can be strengthened by interventions in the early life through school dental health programs.

Keywords: Caries experience, Cross-sectional study, Sense of coherence, Socioeconomic status.

International Journal of Clinical Pediatric Dentistry (2020): 10.5005/jp-journals-10005-1829
\end{abstract}

\section{INTRODUCTION}

Sense of coherence (SOC) is the fundamental concept of Antonovsky's salutogenic theory, which is directed toward the factors responsible for health rather than the illness. Salutogenesis concept elucidates why some individuals stay healthy, even after encountering highly stressful situations, while others suffer disease and illness. ${ }^{1}$ It is learnt that a person with higher SOC is able to cope adequately and find appropriate solutions to challenges (mastery orientation), thereby stays healthy. ${ }^{2}$

SOC is a global orientation that explains the extent to which individual has a pervasive, dynamic feeling of confidence that: (i) the stimuli deriving from one's internal and external environments in his/her life are structured, predictable, and explicable; (ii) the resources are available to one to meet the demands raised by these stimuli; and (iii) these demands are challenges that deserve investment and engagement. ${ }^{1}$ Sense of coherence influences the origin and healing of the disease through effective coping, by avoiding behaviors that adversely affect health, and adopting behaviors that promotes health., ${ }^{1,3}$

It is also hypothesized that $\mathrm{SOC}$ is influenced by socioeconomic status (SES). Higher SES during the early years of life provides experiences that promote the development of strong SOC, whereas the reverse happen in lower SES. ${ }^{4}$ Thus, it is predictable that higher childhood SES is correlated positively with stronger adulthood SOC. ${ }^{5,6}$

It is believed that stronger SOC predicts better oral health outcomes by possessing more number of teeth with low level of dental caries and periodontal disease. ${ }^{7}$ However, there is a paucity of literature regarding the association of SOC, oral health, and SES.
${ }^{1-5}$ Department of Pedodontics and Preventive Dentistry, Vishnu Dental College, Bhimavaram, Andhra Pradesh, India

Corresponding Author: Kakarla Sri RojaRamya, Department of Pedodontics and Preventive Dentistry, Vishnu Dental College, Bhimavaram, Andhra Pradesh, India, Phone: +91 8985774540 , e-mail: rojachowdary28@gmail.com

How to cite this article: Mrudhula KJN, Vinay C, Uloopi KS, et al. A Cross-sectional Study on Sense of Coherence and Its Relationship with Caries Experience and Socioeconomic Status in 11-16-year-old Schoolchildren. Int J Clin Pediatr Dent 2020;13(5):493-496.

Source of support: Nil

Conflict of interest: None

Therefore, a study was carried out to understand the relationship of SOC, caries experience, and SES in 11-16-year-old schoolchildren.

\section{Materials and Methods}

The cross-sectional study design has been approved by Institutional Review Board (VDC/IEC/2014-18). A total of 595 healthy schoolchildren aged 11-16years were selected by stratified randomization method from 5 pre-selected schools of Bhimavaram town, West Godavari district of Andhra Pradesh. Informed consent was obtained from the parents and school authorities. Children who are undergoing orthodontic treatment, suffering from any systemic diseases, in need of special care, and with mixed dentition were excluded from the study. 


\section{Sample Size}

Based on the pilot study, setting the confidence level at $95 \%$, prevalence $49 \%$, and precision $5 \%$, the required sample size was calculated as 384 using the formula $n=\left(Z \alpha^{2} \times p \cdot q\right) / d^{2}$. However, a higher sample size of 650 children was taken to permit for possible non-response, in which 55 children were excluded since they did not meet the inclusion criteria. Hence, the final sample comprised of 595 children.

\section{Data Collection}

Data were collected through a pro forma (given to parents), the SOC questionnaire, and intra-oral examination, which was carried out at the schools.

Parents of the participating children were given a pro forma for recording demographic data (name, age, sex, address and contact number), profession, level of education, and income to assess SES with Kuppuswamy socioeconomic criteria. ${ }^{8}$

SOC of children was recorded with abbreviated version of the SOC-13 item questionnaire that was developed by Antonovsky, which comprises of 13 components on a 7-point Likert-type scale with descriptive end points. ' Question numbers 1, 3, 7, and 10 were negatively framed items; therefore, they were scored conversely so that a high score indicates strong SOC. The total score ranges from 13 to 91 , and a higher score indicates stronger SOC.

Reliability of SOC questionnaire was evaluated with Cronbach's alpha coefficient formula, and the alpha coefficient obtained was 0.89 , which is an acceptable reliability. Questionnaire for recording the sense of coherence was given in both English and local language (Telugu). Questions were explained to children and then they were allowed to answer.

Later, the schoolchildren were examined for caries experience by recording the DMFT index. ${ }^{9}$ Two examiners were calibrated for intra-oral examination at the schools. Kappa test findings for DMFT were 0.88 for intra-examiner, and 0.82 for inter-examiner, indicating an almost perfect consistent agreement.

\section{Statistical Analysis}

The association of sense of coherence with caries experience was analyzed using ANOVA. Multivariate analysis was performed to know the relationship of caries experience with SOC and SES. The total SOC was assessed as a categorical variable divided into tertiles as $t_{1}<33$ (weak), $t_{2}=33-66$ (moderate), and $t_{3}>66$ (strong). Chisquare test was done to analyze the relationship of SOC with SES, age, and gender.

\section{Results}

Among 595 schoolchildren, 35\% children have weak SOC, 34.9\% moderate SOC, and $29.9 \%$ stronger SOC. Sense of coherence has shown inverse relation with the caries experience of an individual, i.e., higher the sense of coherence, lower the DMFT score. There was statistically significant difference between caries experience in individuals with different SOC (Table 1). On multivariate logistic regression analysis, for every oneunit increase in SOC, caries experience decreased by 0.11 unit (Table 2).

There was no statistically significant relation between $\mathrm{SOC}$ and SES suggesting SOC was not influenced by the childhood SES ( $p$ value $=0.09$ ) (Table 3 ). Statistically, SOC scores did not show any significant difference with age ( $p$ value $=0.08$ ) (Table 4$)$ as well as gender $(p=0.19)$ (Table 5).
Table 1: Association of sense of coherence with caries experience

\begin{tabular}{lll}
\hline & \multicolumn{2}{c}{ DMFT } \\
\cline { 2 - 3 } SOC & Mean & $S D$ \\
\hline Weak SOC $\left(t_{1}<33\right)$ & 1.94 & 2.04 \\
Moderate SOC $\left(t_{2}=\right.$ & 1.70 & 2.05 \\
33-66) & & \\
Strong SOC $\left(t_{3}>66\right)$ & 1.45 & 1.84 \\
ANOVA & $\mathrm{F}$ & 2.91 \\
& $\mathrm{P}$ & $0.05, \mathrm{~S}$ \\
Post Hoc Tukey & Weak vs moderate, $p=0.446$ \\
& Moderate vs strong, $p=0.427$ \\
& Weak vs strong, $p=0.043, \mathrm{~S}$ \\
\hline
\end{tabular}

ANOVA and Post Hoc Tukey tests, S-significant; ANOVA-analysis of variance

\section{Discussion}

The sense of coherence (SOC) is a principal conception of salutogenesis which explains the relationship between life stresses and health. The salutogenic theory emphasizes on healthy resources and contributes to the knowledge of maintenance of health. ${ }^{1}$ Adolescents with strong SOC tend to have regular dental check-ups and higher toothbrushing frequency (twice daily or more often). ${ }^{10}$

In the present study, children with stronger SOC were associated with less caries experience. These findings were similar to the observations of Freire et al. in Brazilian population that adolescents with stronger SOC have less caries experience in anterior teeth than those with weaker SOC scores. ${ }^{10}$ Similar findings were observed in Finnish and Indian populations.,11 Lower prevalence of dental caries in individuals with stronger SOC could be because of the fact that increased psychosocial ability promotes health.

The health-promoting role of SOC is through three different ways (i) by modulating emotional tension caused by the stressors; (ii) by adopting healthy behaviors; and (iii) by direct physiological response through the central pathways of the neuro-immune and endocrine systems., ${ }^{1,12}$ The lower caries experience was mainly accounted to the adoption of healthy dental behaviors such as regular dental check-ups, brushing teeth two or more times a day as well as having low sugar intake frequency. ${ }^{13-16}$ These perspectives toward oral health helps in improving oral hygiene, thereby reducing the caries experience.

$\mathrm{SOC}$ is a psychosocial factor that is influenced by various genetic, environmental, and social factors. Among various social factors, childhood SES was considered to play a vital role in the development of SOC. In the present study, SES of the children was assessed using Kuppuswamy socioeconomic status scale, which is a composite scoring system that includes education, head of the family's occupation, and monthly income of the family. ${ }^{8}$ The difference in SOC scores among five socioeconomic groups was found to be insignificant in the present study.

Ing and Reutter observed that SOC score of Canadian women was increased with an increase in the household income. ${ }^{17}$ Bernabe et al. reported that higher childhood SES has favorable association with stronger SOC in adulthood. ${ }^{6}$ This infers that SES shapes SOC, however in the present study, no such correlation was observed. This may be due to difference in the criteria used to categorize the 
Table 2: Table representing the ordinal regression value by multivariate analysis with caries experience as dependable variable and sense of coherence as predictor

\begin{tabular}{|c|c|c|c|c|c|c|}
\hline \multicolumn{7}{|c|}{ Coefficients } \\
\hline & & \multicolumn{2}{|c|}{ Unstandardized coefficients } & \multirow{2}{*}{$\begin{array}{l}\text { Standardized coefficients } \\
\text { ODDS ratio }\end{array}$} & \multirow[b]{2}{*}{$t$} & \multirow[b]{2}{*}{$p$ value } \\
\hline \multicolumn{2}{|l|}{ Model } & $B$ & Std. error & & & \\
\hline \multirow[t]{2}{*}{ Caries experience } & (Constant) & -1.24 & 0.38 & & -3.29 & 0.001 \\
\hline & SOC & -0.08 & 0.03 & -0.11 & -2.75 & $0.006, \mathrm{~S}$ \\
\hline
\end{tabular}

Multivariate analysis, S-significant

Table 3: Relationship between sense of coherence and socioeconomic status

\begin{tabular}{|c|c|c|c|c|c|c|c|}
\hline \multirow[b]{2}{*}{ SES } & \multicolumn{2}{|c|}{ Weak SOC $\left(t_{1}<33\right)$} & \multicolumn{2}{|c|}{ Moderate SOC $\left(t_{2}=33-66\right)$} & \multicolumn{2}{|c|}{ Strong SOC $\left(t_{3}>66\right)$} & \multirow[b]{2}{*}{ Total } \\
\hline & $n$ & $\%$ & $n$ & $\%$ & $n$ & $\%$ & \\
\hline Lower class & 23 & 36.5 & 19 & 30.2 & 21 & 33.3 & 63 \\
\hline $\begin{array}{l}\text { Upper lower } \\
\text { class }\end{array}$ & 36 & 29.8 & 54 & 44.6 & 31 & 25.6 & 121 \\
\hline $\begin{array}{l}\text { Lower middle } \\
\text { class }\end{array}$ & 64 & 35.4 & 65 & 35.9 & 52 & 28.7 & 181 \\
\hline $\begin{array}{l}\text { Upper middle } \\
\text { class }\end{array}$ & 46 & 32.4 & 43 & 30.3 & 53 & 37.3 & 142 \\
\hline Upper class & 40 & 45.5 & 27 & 30.7 & 21 & 23.9 & 88 \\
\hline Total & 209 & 35.1 & 208 & 35.0 & 178 & 29.9 & 595 \\
\hline \multicolumn{8}{|c|}{$p=0.09, \mathrm{NS} ; \chi^{2}=13.81$} \\
\hline
\end{tabular}

Chi-square test, NS-not significant

Table 4: Age-wise comparison of sense of coherence

\begin{tabular}{|c|c|c|c|c|c|c|c|}
\hline \multirow[b]{2}{*}{ Age in years } & \multicolumn{2}{|c|}{ Weak SOC $\left(t_{1}<33\right)$} & \multicolumn{2}{|c|}{ Moderate SOC $\left(t_{2}=33-66\right)$} & \multicolumn{2}{|c|}{ Strong SOC $\left(t_{3}>66\right)$} & \multirow[b]{2}{*}{ Total } \\
\hline & $n$ & $\%$ & $n$ & $\%$ & $n$ & $\%$ & \\
\hline 11 & 7 & 26.9 & 13 & 50.0 & 6 & 23.1 & 26 \\
\hline 12 & 22 & 32.8 & 17 & 25.4 & 28 & 41.8 & 67 \\
\hline 13 & 74 & 36.6 & 66 & 32.7 & 62 & 30.7 & 202 \\
\hline 14 & 76 & 34.2 & 84 & 37.8 & 62 & 27.9 & 222 \\
\hline 15 & 26 & 35.1 & 28 & 37.8 & 20 & 27.0 & 74 \\
\hline 16 & 4 & 100.0 & 0 & 0.0 & 0 & 0.0 & 4 \\
\hline Total & 209 & 35.1 & 208 & 35.0 & 178 & 29.9 & 595 \\
\hline
\end{tabular}

Chi-square test, NS-not significant

Table 5: Gender-wise comparison of sense of coherence

\begin{tabular}{|c|c|c|c|c|c|c|c|}
\hline \multirow[b]{2}{*}{ Gender } & \multicolumn{2}{|c|}{ Weak SOC $\left(t_{1}<33\right)$} & \multicolumn{2}{|c|}{ Moderate SOC $\left(t_{2}=33-66\right)$} & \multicolumn{2}{|c|}{ Strong SOC $\left(t_{3}>66\right)$} & \multirow[b]{2}{*}{ Total } \\
\hline & $n$ & $\%$ & $n$ & $\%$ & $n$ & $\%$ & \\
\hline Male & 93 & 32.6 & 110 & 38.6 & 82 & 28.8 & 285 \\
\hline Female & 116 & 37.4 & 98 & 31.6 & 96 & 31.0 & 310 \\
\hline \multicolumn{8}{|c|}{$p=0.19, \mathrm{NS} ; \gamma^{2}=3.28$} \\
\hline
\end{tabular}

Chi-square test, NS-not significant

children's SES. A composite scoring system was used in the present study rather than household income alone.

In the current study, gender did not influence the SOC of children. Similar findings were observed in South African eighthgrade adolescents and Danish adults. ${ }^{18,19}$ Although there was no gender difference in SOC of adults, Thome and Hallberg, and Hendrikx et al. reported that males have a stronger SOC than females. ${ }^{20,21}$ Dorri et al. also observed that boys are having stronger
SOC than girls in Iranian population. ${ }^{22}$ The gender differences with SOC scores may be due to the differences in social roles played by males and females in diverse communities.

Another factor that was considered in the present study was age. Age of the children did not influence the SOC. Similar findings were reported by Margalit and Eysenck in Israel population. ${ }^{23}$ On the contrary, in a study by Lindmark et al. in 20-80 years old adult Swedish population, it was reported that 20 -year-olds are having 
lower SOC scores than older age-groups. ${ }^{24}$ However, in the present study, a narrow range of age-groups, 11 to 16 years old, were included, which might be the reason for non-influence of age on SOC.

Salutogenesis model states that individuals with strong SOC have increased likelihood to figure out the existing resources to cope with the demands. Thus, stronger the SOC, greater the chances to seek out preventive dental services, which helps in maintaining good oral health. ${ }^{2,25}$ Moreover, SOC is structured mainly by the experiences during the early years of life, such as participation in socially valued decision-making., ${ }^{1,12}$ Therefore, SOC can be strengthened by interventions in the early life through school dental health programs.

\section{Conclusion}

The psychosocial factor sense of coherence has association with caries experience; however, the childhood socioeconomic status did not influence the development of sense of coherence in children. Age and gender of children did not influence the sense of coherence.

\section{References}

1. Antonovsky A. Unraveling the mystery of health: How people manage stress and stay well. San Fransisco: Jossey-Bass; 1987.

2. Antonovsky A. The structure and properties of the sense of coherence scale. Soc Sci Med 1993;36(6):725-733. DOI: 10.1016/02779536(93)90033-Z.

3. Antonovsky A. The sense of coherence as a determinant of health. In: Matarazzo JD, ed. Behavioral health: A handbook of health enhancement and disease prevention. New York: John Wiley and Sons; 1984. pp. 114-129.

4. Geyer S. Some conceptual considerations on the sense of coherence. Soc Sci Med 1997;44(12):1771-1779. DOI: 10.1016/S02779536(96)00286-9.

5. Sagy S, Antonovsky H. The development of the sense of coherence: a retrospective study of early life experiences in the family. Int J Agin Hum Dev 2000;51(2):155-166. DOI: 10.2190/765L-K6NV-JK52-UFKT.

6. Bernabe $E$, Watt RG, Sheiham A, et al. The influence of sense of coherence on the relationship between childhood socioeconomic status and adult oral health related behaviours. Community Dent Oral Epidemiol 2009;37(4):357-365. DOI: 10.1111/j.16000528.2009.00483.x.

7. Bernabe E, Watt RG, Sheiham A, et al. Sense of coherence and oral health in dentate adults: findings from the Finnish health 2000 survey. J Clin Periodontol 2010;37(11):981-987. DOI: 10.1111/j.1600051X.2010.01604.x.

8. Oberoi SS. Updating income ranges for Kuppuswamy's socioeconomic status scale for the year 2014. Indian J Public Health 2015;59(2):156-157. DOI: 10.4103/0019-557X.157540.

9. World Health Organizatio n. Oral Health Surveys: Basic Methods. 5th edn., Geneva: World Health Organization; 2013.

10. Freire MCM, Sheiham A, Hardy R. Adolescents' sense of coherence, oral health status, and oral health-related behaviours. Community
Dent Oral Epidemiol 2001;29(3):204-212. DOI: 10.1034/j.16000528.2001.290306.x.

11. Viswanath D, Krishna AV. Correlation between dental anxiety, sense of coherence (SOC) and dental caries in school children from Bangaluru north: a cross-sectional study. J Indian Soc Pedod Prev Dent 2015;33(1):15-18. DOI: 10.4103/0970-4388.148962.

12. Antonovsky A. The salutogenic model as a theory to guide health promotion. Health Promot Int 1996;11:11-18. DOI: 10.1093/ heapro/11.1.11.

13. Bernabe $E$, Kivimaki $M$, Tsakos $G$, et al. The relationship among sense of coherence, socio-economic status, and oral healthrelated behaviours among Finnish dentate adults. Eur J Oral Sci 2009;117(4):413-418. DOI: 10.1111/j.1600-0722.2009.00655.x.

14. Bernabe E, Newton JT, Uutela A, et al. Sense of coherence and fouryear caries incidence in finnish adults. Caries Res 2012;46(6):523-529. DOI: 10.1159/000341219.

15. Lindmark $U$, Hakeberg $M$, Hugoson A. Sense of coherence and its relationship with oral health-related behaviour and knowledge of and attitudes towards oral health. Community Dent Oral Epidemiol 2011;39(6):542-553. DOI: 10.1111/j.1600-0528.2011. 00627.x.

16. Savolainen JJ, Suominen-Taipale AL, Uutela AK, et al. Sense of coherence as a determinant of toothbrushing frequency and level of oral hygiene. J Periodontol 2005;76(6):1006-1012. DOI: 10.1902/ jop.2005.76.6.1006.

17. Ing JD, Reutter L. Socioeconomic status, sense of coherence and health in Canadian women. Can J Public Health 2003;94(3):224-228. DOI: 10.1007/BF03405071.

18. Ayo-Yusuf OA, Reddy PS, van den Borne BW. Adolescents' sense of coherence and smoking as longitudinal predictors of self-reported gingivitis. J Clin Periodontol 2008;35(11):931-937. DOI: 10.1111/j.1600051X.2008.01319.x.

19. Due EP, Holstein BE. "Sense of coherence", social class and health in a Danish population study. Ugeskr Laeger 1998;160(51) :7424-7429.

20. Thome B, Hallberg IR. Quality of life in older people with cancer-a gender perspective. Eur J of Cancer Care (Engl) 2004;13(5):454-463. DOI: 10.1111/j.1365-2354.2004.00471.x.

21. Hendrikx T, Nilsson M, Westman G. Sense of coherence in three crosssectional studies in northern Sweden 1994, 1999 and 2004-patterns among men and women. Scand J Public Health 2008;36(4):340-345. DOI: $10.1177 / 1403494808089560$.

22. Dorri M, Sheiham A, Hardy R, et al. The relationship between sense of coherence and tooth brushing behaviours in iranian adolescents in Mashhad. J Clin Periodontol 2010;37(1):46-52. DOI: 10.1111/j.1600051X.2009.01497.x.

23. Margalit M, Eysenck S. Prediction of coherence in adolescence: gender differences in social skills, personality, and family climate. J Res Pers 1990;24(4):510-521. DOI: 10.1016/0092-6566(90)90036-6.

24. Lindmark U, Stenstrom U, Gerdin EW, et al. The distribution of "sense of coherence" among Swedish adults: a quantitative crosssectional population study. Scand J Public Health 2010;38(1):1-8. DOI: $10.1177 / 1403494809351654$

25. Eriksson M, Lindstrom B. Antonovsky's sense of coherence scale and relation with health: a systematic review. J Epidemiol Community Health 2006;60(5):376-381. DOI: 10.1136/jech.2005.041616. 